

\section{Newcastle University e-prints}

Date deposited: 8 June 2010

Version of file: Author, final

Peer Review Status: Peer Reviewed

\section{Citation for published item:}

Hind EJ, Hiponia MC, Gray TS. From community-based to centralised national management-A wrong turning for the governance of the marine protected area in Apo Island, Philippines?. Marine Policy 2010,34 154-62.

\section{Further information on publisher website:}

http://www.sciencedirect.com/

\section{Publishers copyright statement:}

This paper was originally published by Elsevier, 2010, and can be accessed (with permissions) from the DOI below:

http://dx.doi.org/10.1016/j.marpol.2009.04.011

Always use the definitive version when citing.

\section{Use Policy:}

The full-text may be used and/or reproduced and given to third parties in any format or medium, without prior permission or charge, for personal research or study, educational, or not for profit purposes provided that:

- A full bibliographic reference is made to the original source

- A link is made to the metadata record in Newcastle E-prints

- The full text is not changed in any way.

The full-text must not be sold in any format or medium without the formal permission of the copyright holders.

Robinson Library, University of Newcastle upon Tyne, Newcastle upon Tyne. NE1 7RU. Tel. 01912226000 


\title{
From community-based to centralised national management - a wrong turning for the governance of the marine protected area in Apo Island, Philippines?
}

$$
\text { E.J. Hind (a) *, M.C. Hiponia (b) and T.S. Gray (c) }
$$

(a) School of Political Science and Sociology, National University of Ireland, Galway, Ireland

(b) Department of Sociology and Anthropology, Silliman University, Dumaguete City, Negros Oriental, 6200 Philippines

(c) Politics, School of Geography, Politics and Sociology, Newcastle University, Newcastle upon Tyne, NE1 7RU, UK

*Corresponding author

\begin{abstract}
Before the mid-1990s, Apo Island, Philippines was often described as one of the world's best examples of community-based marine management. This paper studies the less-documented transition of the island during the late-1990s from community-based management to centralised national state management. Extensive interviewing of islanders has revealed deep misgivings about the centralised regime - the Protected Area Management Board (PAMB). PAMB's aim of implementing the National Integrated Protected Areas Systems (NIPAS) Act was initially looked upon favourably by islanders, but it has lost that support because of its exclusion of stakeholders from management and its poor institutional performance. The paper's conclusion is that the implementation of the NIPAS Act highlights the limitations of top-down management, and that there is a need to restore an element of local stakeholder participation in the governance of Apo's MPA. A system of co-management between community and national state actors is essential to ensure the long-term sustainability of Apo's marine resources.
\end{abstract}

Keywords: marine protected area; community-based; state-led; co-management; Apo Island; Philippines

\section{Introduction}

Marine protected areas (MPAs) have been claimed as one of the most important tools for coastal resource management. For example, it has been argued that they provide insurance against collapses of fish stocks from overfishing [1]. A proliferation of MPAs would thus seem a sensible strategy to help secure the value of coastal environments for future generations. However, it has been found that only $9 \%$ of MPAs achieve their management objectives [2] ${ }^{1}$, and the poor social and ecological performance of most of them has led critics to ask whether there is a future for MPAs in tropical developing nations [3]. The crucial issue is whether the key to the success or the failure of an MPA lies in its management system, and in particular, whether that system incorporates stakeholder participation in its decisionmaking processes.

The Philippines was the site of some of the earliest MPAs and it now boasts well over 300, which constitute the country's primary tool for coastal resource management. Two formats of MPA exist in the Philippines: first is the community-based 'sanctuary', allowing local stakeholders to manage their own resources, empowered by the Local Government Code of 1991 [4]. This code, which is a permissive Act of legislation, enables the Barangay (local community groups) to partner with their local municipalities, passing ordinances that create MPAs and laws to govern them up to $7 \mathrm{~km}$ offshore. The enactment of the Fisheries Code in 1998 [5] has allowed an extension of this community control of fisheries up to $15 \mathrm{~km}$ offshore. The second MPA format is the centralised national model, which is a prescriptive, top-down method of ensuring a 'protected land and seascape' [6]. The National Integrated Protected Area Systems Act of 1992 (NIPAS) [7] prescribes the creation of MPAs with a more centralised structure than those created through the Local Government Code. An NIPAS MPA is governed by a Protected Area Management Board (PAMB), mostly comprising officials appointed by the national Department of the Environment and Natural Resources (DENR), and led by a site-based administrator who serves as the DENR chief operating officer on the protected areas, and is called the Protected Area Superintendent [8]. In addition to enforcing NIPAS, the PAMB is authorised to create

\footnotetext{
${ }^{1}$ Though Jones [9] points out that there was insufficient evidence in $71 \%$ of the cases to assess their performance.
} 
its own legislation through Section 9 of the Act, which also requires a general management plan for each NIPAS area.

The contrast between the community-based MPA format of the Local Government Code (coupled with the Fisheries Code) and the centralised national MPA format of the NIPAS provides the rationale for this study. Many emphasise the value of decentralised community-based management in the Philippines, and how much it has influenced other nations' coastal resource management programmes [10]. However, despite widespread acknowledgement of the worth of the community-based management principle, the Philippine Government introduced NIPAS to replace community-based management with national government direction. It did so because it claimed there was a danger that the community might choose to turn its back on conservation objectives, and exploit the MPA for economic benefit, as happened in Sumilon. This study assesses the effects of that centralisation process, focussing on the question of whether the implementation of NIPAS in Apo was necessary.

The next section explains the background to Apo Island, particularly its geographical and demographic characteristics and its history of management systems. In section 3, the methodology of the study is outlined, together with its theoretical perspective. Section 4 presents the results of the fieldwork, evaluating the performance of the current centralised management system in Apo by identifying six major themes that emerge from the data. The discussion section 5 assesses the implications of these results for Apo's future, and the wider implications for the Philippines and beyond. Concluding remarks in section 6 point to the future for marine governance in Apo Island.

\section{Background to Apo Island}

\subsection{Geography}

The Apo Island Protected Landscape and Seascape General Management Plan [8] describes Apo's geography. Approximately $63 \mathrm{ha}$ in size, it is located in the Sulu Sea of the Central Visayan region in the province of Negros Oriental, and falls under the municipal jurisdiction of Dauin. The island's fringing reefs have high biodiversity, all rated very good to excellent, displaying $72.8 \%$ cover of live hard and soft coral. The marine sanctuary is a 15 ha area to the east of the island (see Figure 1).

\section{FIGURE 1 PLACED HERE}

Although not categorised as pristine, the terrestrial portion of the island, mostly consisting of secondary tropical forest, mangroves, sandy beaches and open uplands of agricultural and barren designation, is classified as of high ecological importance and is a protected area. The most recent population survey estimated a total of 760 people comprising 151 households [8]. The population growth rate is a relatively low $1.7 \%$, but the fact that 215 of the residents in 2001 were enrolled at the island's elementary and high schools in 2006-2007 shows that the population structure is skewed towards younger age groups, an inference confirmed by the qualitative observations of this study. It seems that a high proportion of middle-aged inhabitants leave the island for work or other reasons, leaving a fairly low proportion of older inhabitants. The island's three major livelihoods are fishing (it is reported that 54\% of Apo residents derived their income directly or indirectly from fishing [8]), tourism, and working in MPA management as employees of the PAMB (see Table 1).

\section{TABLE 1 PLACED HERE}

Other minority livelihoods include farming and off-island employment. The island's Barangay is made up of seven Puroks (the smallest Philippine political unit), each of which looks after its own minor political affairs. Table 1 shows that households in Puroks 1 to 3 are generally more involved in tourism and MPA management; that the livelihoods of those in Puroks 5 to 7 are more dominated by fishing; and that Purok 4, situated geographically in the centre of the settlements, has a more evenly spread employment profile. This distribution of livelihood activities is explained by the fact that Puroks 1 to 3 contain the main tourist landing point, the PAMB office and the two resorts, whereas Puroks 5 to 7 are situated closer to the traditional fishing grounds (see Figure 1).

\subsection{Management system}

The history of the MPA management system at Apo is documented in Figure 2 


\section{FIGURE 2 PLACED HERE}

The key watershed in this history was the establishment of PAMB in 1998, which signalled the start of a centralised coastal resource management system. Before that, the community-based phase of management was seen by many as highly successful, with Apo becoming one of the first MPAs to demonstrate spillover of fish biomass to adjoining fishing areas [11]. In 1996, Apo was awarded the title of "Best Managed Reef in the Philippines" by the Coral Reef Information Network of the Philippines (PhilReefs), citing the islanders' efforts and dedication in setting up and maintaining their community-based management program as the reason for the award [8]. It was calculated that during the management of the Marine Management Committee, made up of local stakeholders, fish stocks in the sanctuary increased by up to eightfold for some species [10]. Further study showed that these increases were coupled with significant increases in catch per unit effort of fisherman fishing within $200 \mathrm{~m}$ of the no-take sanctuary, increasing by $50 \%$ during the first 16 to 19 years of protection [11]. These positive findings of natural scientists were complemented by the results of socio-economic studies. During the course of 21 interviews with fishermen in the early 1990s, it was discovered that $100 \%$ of the fishermen backed the community-based management of the sanctuary, and that 10 of the 21 noted a beneficial economic effect for their families from tourism [12]. According to one study, during the 1990s, the industry was annually returning between US\$31,900 and 113,000 of profit [13].

So why was this apparently successful community-based management in Apo designated by DENR in 1994 for NIPAS management? Three reasons have been suggested. First, there were some concerns about what the General Management Plan [8] called "the lack of awareness of some community residents....about the importance of protected area management". The second reason, linked to the first, is more complicated. In Sumilon Island, another pioneer Philippine MPA, similarly sized to Apo though uninhabited, the initial community-based management was successful, but a sudden electoral change in the local municipality that gave power to a party that had campaigned actively against the MPA, led to an unofficial re-opening of no-take areas [10]. This change in leadership eroded years of hard work growing fish biomass, and fish stocks collapsed. It is likely that the example of Sumilon led the DENR to declare Apo's MPA under NIPAS as a precautionary measure to protect it from any similar changes in local government. As a PAMB board member put it, "I think they felt they [MPAs] should be protected from the abuses of politicians". The validity of this concern has been questioned by some academics familiar with the Apo case, but they acknowledge that the cases of both Sumilon and Apo have influenced the content of NIPAS [10]. The third reason, suggested by an expert in Philippine environmental law, is that NIPAS had to obtain funds from Apo to protect adjacent areas that did not generate their own income from user fees: "Whether you like it or not actually, the protected area system is integrated. It's an ecosystem! So Apo is in the Bohol Sea, you need to take care of Tanyon Strait [a body of water near Apo] you know, because you can't separate Apo from this, from the entire ecosystem, and that's the job of the national government. So somehow the national government has to have money to protect these areas." Whether these reasons justified the imposition of top-down national state-management, rather than a system of co-management, is, however, disputable.

\section{Methodology}

The fieldwork data was collected during six weeks in April and May 2008 in two stages. The first stage was to administer questionnaires, which contained a mixture of closed and open responses, taking care to survey a representative number of respondents from each Purok. The subject matter for the second stage - key informant interviews and focus group discussions - was drawn from observational notes taken during the first stage. Interviewees and focus group participants were chosen by both preidentified means and random encounters. The effectiveness of this fieldwork in generating valuable data was enhanced by two decisions: first, to avoid research fatigue. Apo is one of the world's most frequently studied MPAs and the community has been subjected to many previous surveys. Techniques employed by similar studies [14] were used to establish good relationships with the islanders by explaining that the aim was to discover their own perceptions of the management system (PAMB). A total of 151 questionnaires were administered, a significantly higher number than in previous studies on Apo. The second decision, made because the research would be analysing a change over time, was to target community elders, because a previous study showed that, although the elderly can be harder to access, they often reveal crucial information missed by surveys that only target the most easily accessible community members [15]. Accordingly, the interviewees included founding members of the 
Marine Management Committee, who were able to provide information about the setting up of the sanctuary that nobody else could provide.

In analysing the data obtained from the questionnaires, quantitative statistical techniques were used, including Mann-Whitney tests to assess if there were statistically significant differences between the different populations surveyed, particularly by livelihood. In analysing the data obtained from the key informant interviews and the focus group discussions, the qualitative technique of open coding was used following the interpretive approach [16], to look behind the statements made by respondents to grasp their significance.

The theoretical perspective informing this methodology is MPA governance theory as set out by Jones [9], who distinguishes between a top-down and a bottom-up approach, and argues, along with other writers such as Brunckhorst, Bridgewater, Ballantine, Kelleher, Reccia, Mascia, Wilson, Raakjaer Nelsen, Degnbol, Jentoft and Mikalsen, that the two approaches should be combined in a system of comanagement: "In order to combine strategic scientific and resource management objectives with the need to promote stakeholder cooperation, it is becoming increasingly recognised that it is necessary to combine top-down and bottom-up approaches by adopting collaborative management (co-management) approaches which provide for stakeholders and relevant government agencies to jointly manage MPAs".

\section{Results}

\subsection{Introduction}

The results of this study are divided into six themes which emerged from the questionnaires, the interviews and the focus groups: alienation at the PAMB's exclusion of stakeholders from participation in decision-making; objection to its lack of financial transparency; resentment at its failure to protect fishing grounds from tourist diving activities; disappointment that it had not raised the islanders' socioeconomic standard of living; anxiety about its poor environmental performance; and overall judgement on the PAMB.

\subsection{Exclusion of stakeholders from participation in decision-making}

A theme which repeatedly came out of the fieldwork was criticism of the lack of stakeholder participation in management decision-making. A former Barangay leader said that "the people...had a system that is run by the people, and then comes the new one which is run by the national [government]". It has been argued by some commentators that although there were some initial misgivings about the formation of the PAMB [17], the DENR wisely let Apo residents continue a style of coastal resource management. But other research [18] [19] found tension in the relationship between local stakeholders and national government, to the extent of the disempowerment of the local population. The current study confirmed that tension, which began with the very inception of the centralised system. Former MMC members and Barangay officials disclosed that Silliman University had recommended declaration under NIPAS, and that as they had always been impressed with the university's technical assistance in the past, they were happy to follow its advice on NIPAS registration. However, few members of the wider community remember formally endorsing the change, and respondents claimed that very few people had been consulted about, or asked to approve, the change in management. The recurring narrative was that villagers had attended an initial hearing on the plans for the change and at that meeting they had signed a piece of paper, proving their attendance. Some claim in hindsight that their signatures were instead used to ratify NIPAS designation, prompting one fisherman to say that "PAMB entered the house without passing through the door. They came through the window!" Whether this claim is based on fact rather than paranoia, it indicates that there was considerable ignorance among islanders about the new regime. For instance, $53 \%$ of respondents did not know of the existence of NIPAS, and only one focus group participant had attended an information session on the Act, and since this session had been conducted in English, not his native language, he was unable to understand the proceedings.

In its decision-making, PAMB was accused of displaying the kind of approach attributed to top-down management [9]. For example, PAMB management was commonly criticised for introducing too many prohibitions and restricting personal freedom, leading one islander to say that life on the island "is like being in prison!" The legitimacy of many of these prohibitions rested on their endorsement by the 
General Management Plan [8], but the only islanders who were aware of the Plan were Barangay officials and those on the PAMB board. The most feared threat expressed by Barangay residents was potential forced removal from the island, as residents had heard of this taking place in other government-controlled areas. Whether justified or not, this fear was related to one of the main environmental concerns of the General Management Plan [8] - that a growing population was hastening environmental degradation by increased human interaction with the land, such as extending farmlands, and Section 10 of NIPAS [7] contained legislation that permitted forced removal. Although the Protected Area Superintendent stated that nobody would be evicted who had lived on the island five years before the declaration of NIPAS, according to the General Management Plan [8], as a Barangay councillor pointed out, this was only assured if a resident could produce documentation proving tenure before 1989. Whilst there has been little immigration since 1989, which in principle means that the threat of eviction is not an issue, land tenure on the island is mostly by tax declaration (90\%) [8] and many land claimants are worried that they do not possess the paperwork to prove that they owned land before 1989. Many residents expressed anger at this potential threat, one saying that he "will murder those who remove them. The one who did this to us will be the first to burn!"

The General Management Plan [8] was claimed to be formed through the "collective efforts of the community", but even the Protected Area Superintendent conceded that the only community input was from the Barangay leader, who in her role as a PAMB member, conveyed community opinions to the PAMB board. Barangay officials asserted that the Barangay council was ignored in PAMB decisionmaking, and all the Barangay councillors interviewed stated that the PAMB did not listen to their decisions, one saying that "in the present scenario, the PAMB or the DENR will say we are the superior, because we came from the national government. So the Barangay will automatically give way and just say yes to the policy." For instance, there was a proposal to build a new development of holiday cottages on the beach fronting the marine sanctuary or MPA by a local resident who appears to have been backed by non-resident, private investors. The Barangay council rejected the proposal, which would have obstructed the mangrove pond where fishermen store their boats for safety during storms, primarily because the villagers were almost unanimously against it. But the PAMB ignored this rejection and granted a permit for the project, despite the claim by the Protected Area Superintendent in an interview that "there will be no cottage construction there without their consent". Whilst Apo Island is far from being a corporate tourist destination, unlike other Philippine sites such as Borocay Island, residents worry that any investment from outside the island could set a precedent that would encourage rapid tourism growth. The islanders would prefer tourism to be limited to the current level, where they could benefit from any income from user fees whilst the culture and peaceful nature of the island remained largely unchanged.

Even within the PAMB itself there was evidence of elitism, as certain PAMB members asserted that some PAMB board members held significantly more power than others. For instance, local members of the PAMB often referred to non-local members as "they", suggesting a split in the board, apparently caused by top-down actions of those representing the national government. An ex-PAMB member said that "They will prioritise what they want instead of using the plan [the General Management Plan]", while the municipal mayor, also a PAMB member, was critical of the way "they" no longer considered fishermen in "their" management plan, and he claimed that a minority of PAMB members wrote the plan and the remaining members were just expected to sign it. Although these views were contested by a DENR employee and PAMB member who believed the PAMB to be made up of a well-balanced selection of islanders and non-islanders, all with a democratic mandate to make decisions on behalf of the people of Apo, most Apo islanders appeared to believe that they were ignored by PAMB. Although $39.3 \%$ of respondents believed they could voice their opinions 'whenever they wanted' or 'quite often', $60.3 \%$ believed the chances to do this were 'not often' or 'not at all'. Even including those who believed it was easy to voice opinions, $41.1 \%$ said their opinions were 'not at all' listened to, while $45 \%$ said 'sometimes', and only $12.6 \%$ said they were listened to 'often' or 'always'.

One respondent was afraid even to respond to interview questions as she did not want people to hear her voicing anti-PAMB opinions. A focus group participant claimed that only three people controlled the island, while the mayor asked rhetorically: "But what happens now in this PAMB, NIPAS? There is a matter of five people talking there, what they have agreed, immediately becomes a law...it's a kangaroo court!" Another focus group respondent said that by contrast to Silliman University, "PAMB just do as they please with no consultation. They are stupid for not consulting...Just because they are national it is not OK". Some questioned the legitimacy of the board, criticising an institution where so few people controlled the lives of so many, and residents attempted to present a petition (signed by 
approximately $15 \%$ of the island's total population) to PAMB asking it to leave the island, but they received no response. Others saw the hand of DENR behind PAMB: for instance, the Mayor claimed that "mostly everything, almost all [is] 100\% managed through the DENR's office". A PAMB board member observed that "although the membership is localised, the authority is really national", because it was effectively controlled by DENR, which, even when resolutions were passed by PAMB, prevented them from being implemented by not releasing the money required to fund them. This member said that as a result, "Nobody comes to meetings anymore, because for what? You come... we decide... we have a revolution... nothing's done about it!" The uniform opinion of interviewees and focus group participants was that if the PAMB were to continue to exist, a majority of local islanders should comprise the board, while some respondents preferred an entirely elected board, not the quasielectoral system proposed by section 11 of NIPAS [7]. As the Mayor put it, "No project with the national government without the co-operation of the local people will be successful...nothing will be successful if the people are not in the front line". These sentiments clearly endorse a regime of comanagement.

\subsection{Lack of financial transparency}

Another recurring theme that emerged from respondents was the lack of financial transparency, an issue claimed to be the major problem with the PAMB management [20]. The General Management Plan [8] stated that $75 \%$ of fees collected should be reinvested in management of the protected area, with $25 \%$ going to the national government. From December 1999, when the DENR began collecting fixed fees, to June 2007, the General Management Plan [8] declared collections of 17,326,549 Pesos (approx. US\$ 400,000), which was considerably more than had previously been collected by the community-based Barangay management, when the fee was a donation. Despite this increased revenue, however, in the opinion of most islanders, they had hardly benefited at all from the collections. Of the islanders interviewed, $79.5 \%$ said they had no idea how these funds were used; and of the $20.5 \%$ who said that they did know, $54.8 \%$ said that the fees were used 'poorly' or 'very poorly'. Although 13 people rated favourably PAMB's use of the fee, these respondents were mostly employed by the PAMB, and it is unlikely that they would criticise their employer, even in a confidential survey (their average score of 6.04 for fee use was significantly different $(w, p=0.042)$ from that of non-PAMB workers' average score of 2.92). During the community-based era, fee money stayed on the island and was released by the Barangay when needed, but under the PAMB, it passed up through the DENR hierarchy and then to the Department of Budget and Management before the $75 \%$ of the fees designated for Apo MPA management was (theoretically) returned. This process has led to lengthy delays in returning the $75 \%$, and to accusations that the $75 \%$ is never returned in its entirety. Even the General Management Plan [8] complained that "the continuous delays in the release of the $75 \%$ share... seriously affected the implementation of daily operation...in the protected area such as sea patrols [and] monitoring of dive rangers in diving sites". And a PAMB member protested that "you have to beg for the 70\%! And that's supposed to be yours under the law". Similarly, the Protected Area Superintendent (PAMB's chief executive) referred to "one big problem in managing the reserve there for me... That is the...75\% share of the local community...it's a long process to get back our $75 \%$ share...this time it's already five months, and it's still in the last office, the Department of Budget and Management...how can we operate or maintain the protected area without our financial [resources]?" Commenting on this situation, the Mayor declared that, "the people of the island feel the agony of being slaves and...beggar(s) of their own money and resources."

Although some fishermen criticised the Barangay officials' handling of money in the community-based management era, suggesting that donations from foreign donors had been misused and that there were other forms of corruption, many more claimed that the national regime was corrupt, in that money was being misused either at the DENR offices or at the offices of the national Department of Budget and Management (DBM). For example, an ex-PAMB member claimed that the Apo Island money had been used to pay for air-conditioning in DENR's office in Dumaguete. The Mayor called for a full audit of all institutions involved in management. Another respondent said that "PAMB get rich and the people get poor!", and that "PAMB are millionaires!", and he proposed that PAMB's revenue and expenditure figures should be published for the whole Barangay to view. A fisherman reported that he had once asked an ex-Protected Area Superintendent if he could see the expenditure figures, and he recalled that in them was an invoice for a hand tractor to cultivate rice fields, yet there was neither a hand tractor nor a rice field on Apo Island. 
A minority of respondents praised the PAMB for purchasing medicines for the village (even some Barangay health workers confirmed that the PAMB had donated funds to buy medicines); sponsoring the Barangay youths to attend college; and partially funding a new high school. But other interviewees, including the mayor and an ex-Barangay leader, claimed that these initiatives were not funded by the PAMB but by the municipality, the Barangay, or private donors..The projects that were most commonly requested by islanders of PAMB were an expanded high school, a health centre and a youth centre, but respondents said these projects had not materialised, and instead two unwanted constructions were built - a second PAMB office in Cogon and a view deck for tourists. The PAMB did complete one project that the community requested - providing a boat that could be used in medical emergencies and to ferry children to school free of charge. However, the boat has not been used as intended, proved by many islanders citing an example of when a Barangay member died on the neighbouring island of Mindanao, the community were not allowed to transport the body back to Apo, and not one of the youths questioned in the study had yet travelled on the boat to school. The islanders complain that the boat is now exclusively used as transport for PAMB staff. In its defence, the PAMB's General Management Plan [9] states that the $75 \%$ of fees collected is solely for maintaining and managing the protected area: there is no budget set aside for livelihood development.

\subsection{Failure to protect fishers from tourist diving}

Respondents were heavily critical of PAMB for what they saw as its failure to protect fishers from the marine activities of tourist divers. Of the people surveyed, $72.8 \%$ believed that diving was a serious threat to the future of fishing, because of the disturbance of fish in the sanctuary that prevented them spawning, and the scaring of fish by divers' bubbles and camera flashes in the non-sanctuary areas. As a result of the fish being scared, fishermen and other resident groups believed the fish were harder to catch, because they now lived in deeper water. PAMB was criticised for not preventing the continued incursion of divers into traditional fishing areas - frequently the number of divers in the sanctuary per day exceeded the 15 prescribed by the General Management Plan [8]. One focus group participant claimed that PAMB chose not to crack down on illegal diving because tourists were more lucrative than fishers: "This is fishing season, but still they do not enforce the rules on diving, as they still favour tourism. Obviously because PAMB get more fees". The PAMB's ineffective patrolling of the fishing grounds was also due to a lack of capacity caused by its underfunding of the Bantay Dagat (marine police) and dive rangers (see section 4.6). Fishermen had become frustrated and were starting to take matters into their own hands. For instance, in the interviews and focus groups there were several accounts of fishermen throwing rocks at divers when they saw their bubbles in the fishing grounds. It is no surprise, therefore, that in the fieldwork survey, the community as a whole rated PAMB's fishery management at just 3.99, and that the households which only practised fishing rated it significantly (w, $\mathrm{p}<0.001$ ) lower at average 2.16 compared to 5.20 of households with no fishermen.

On the other hand, some respondents, including divers, criticised fishermen for using too many fish traps, and the General Management Plan [8] described fishermen employing fish traps as "unscrupulous". Fishermen revealed in a focus group that they knew their fish traps were harming the corals, but claimed they had little choice, since because the number of divers had increased so greatly, the only way they could catch fish was by fishing deeper (including placing fish traps over the coral reefs).

\subsection{Socio-economic standard of living}

The most praised impact of PAMB by interviewees and focus group participants was its creation of jobs [8] on the island, benefiting 32.5\% households questionnaired in the survey. These jobs included employment as Bantay Dagat, dive rangers, municipal ordinance workers, visitor assistance personnel and PAMB office workers. Opinions were mixed on whether the Barangay would continue to support these positions if the PAMB left the island. Feedback from PAMB employees and tourism workers was also positive, describing new opportunities for economic diversification and increased incomes from tourism. An opinion shared by several survey respondents was that as long as people made the effort to work they would be rewarded.

However, many respondents reported no improvement or a worsening in their material quality of life one observing that "Corals get good, but people (are) still poor." This negative picture is supported by survey findings that rated the current socio-economic situation on the island at 4.62 , and the effectiveness of the management in addressing socio-economic issues at 3.87 . Women t-shirt sellers 
said that they had started selling t-shirts to supplement their husbands' decreasing incomes from fishing. Survey results showed $51.7 \%$ of households involved in tourism, but with $77.5 \%$ involved in the majority livelihood of fishing, there are worries that those in this sector were suffering the most. One hotel worker declared that he was sad for the fishermen, "especially when they see I am doing well from tourism, but they have no fish." The survey indicated that the lower position of the fishermen was highly significant $(\mathrm{w}, \mathrm{p}=0.001)$ : in households involved only in fishing, the fishers' socio-economic situation was rated only 3.09 against a score of 5.10 for households not involved in fishing. Fishing households' and non-fishing households' ratings of PAMB's socio-economic management were also highly significant $(\mathrm{w}, \mathrm{p}<0.001)$, with scores of 2.58 and 4.68 respectively. Moreover, at the time of the research, PAMB employee salaries had not been paid for 5 months, and past delays of up to 11 months were reported.

Focus groups reported that during the community-based management period, the Barangay was richer, and households enjoyed a higher quality of life - one illustration being that the MMC created a "calamity fund" used for rebuilding the houses of residents damaged or destroyed in storms.. Respondents stated that they would like to see the $75 \%$ of fees collected by PAMB spent on projects that enhanced their quality of life, something which a large majority affirmed as not having happened so far. They wanted projects such as improved learning facilities, but all they saw were projects that benefited only the managers themselves (such as the PAMB office), or the tourists (such as the view deck).

\subsection{Poor environmental performance}

On the face of it, PAMB's environmental performance seems very good, for four reasons: first, the condition of Apo's coral reef is still of the high quality that some point out [13] makes it so attractive to tourism - a fact confirmed by both the GMP [8] and residents who rated the reef's quality at an average score of 6.77 and were complimentary about the PAMB's management of it, scoring that 6.45. Second, the General Management Plan [8] reported that a survey conducted by Silliman University Marine Laboratory in 2002 indicated that fishers were catching more fish at a lower rate of unit effort than in previous years, and that this could be attributed to successful environmental management. Third, respondents judged that the PAMB had managed dive boat activities well, scoring them 7.10 for that action, noting in particular that their placing of mooring buoys for dive boats had dramatically curtailed anchor damage. Fourth, PAMB was perceived by some islanders to show strong management in the face of some violations, fining one diver P 18,500 (approx. US\$ 400) for destroying a fisherman's fish trap.

However, the fact remains that the PAMB has added little to the pre-existing environmental protection afforded by community-based CRM. Indeed, Table 4.1 shows that although PAMB's management

\section{TABLE 4.1 PLACED HERE}

ratings were positive for its overall management of the sanctuary and for boat control, they still had the lowest environmental ratings of all the surveyed institutions. PAMB's relatively poor environmental stewardship rating was partly due to its other failings, especially its financial irregularities. The overbureaucratic system which delayed the $75 \%$ of collected fees that funded the Apo Island Protected Landscape and Seascape management, and the mismanagement and alleged corruption that reduced this $75 \%$, meant that the enforcing bodies of the Bantay Dagat and dive rangers were severely underfunded. Both agencies said they were unable to do the job to the best of their ability as they did not have the equipment they needed. For instance, the Bantay Dagat could not apprehend illegal fishers in their fishing grounds because they did not have boats fast enough to catch them, and the boats were rarely fuelled, while the dive rangers could not monitor tourist dives because their ranger station lacked basic equipment.

Moreover, it was a common view of respondents that the PAMB had not arrived on the island for environmental reasons at all. One resident said that "it appears they are more interested in money than protecting the environment", and so they favoured tourism because it brought in revenue. In addition to the broken dive regulations (see section 4.4), it is common to see the limit of 32 snorkelers in the sanctuary per day being exceeded, many of these snorkelers standing on the delicate corals. Some respondents claimed that environmental protection was due more to the residents' stewardship than to the PAMB's interventions: "Forget PAMB! The people are the ones that protect the island. Without the 
people there would be no respect for the law!" were the words of one Barangay councillor. A former Barangay leader asked, rhetorically, "So why is this place protected? It's from us! Not from the DENR. The DENR is just here to collect money". The islanders claimed that they could draw on Silliman University for expertise on coral reefs, and pass on that expertise to their children to ensure the island's future. Also they could purchase their own mooring buoys and patrol boats. Even the General Management Plan [8] recognized the islanders' instinctive commitment to environmental stewardship: "Without...actually realizing it, the residents of the island...[have] been practising ecotourism for the past twenty years as [a] direct result of their community-based marine conservation program." By contrast to Sumilon, where, local stakeholders saw and embraced the benefits of increased fish catches, but never truly understood that the benefits were derived from continuous environmental protection [10], when the scientists from Silliman University initiated the community-based management of the Apo MPA, they spent much more time on marine environmental education and this is one of the key factors in forming the attitudes of the Apo residents towards sustainable management of the MPA. Many islanders recounted the role of Silliman University in the setting up the sanctuary as positive, one thanking them by saying, "God thank you Silliman for the future of our children!"

\subsection{Overall verdict on the PAMB}

The sixth and final theme is wider than the other themes, consisting of the overall verdict that was passed on the PAMB. The data from which this verdict is drawn is the questionnaire survey, presented in Figure 4.2, which tracks respondents' rank order preferences for eight theoretical modes of fisheries governance in Apo. Importantly, the most popular mode of governance

\section{FIGURE 3 PLACED HERE}

is a form of co-management shared between the Barangay and the municipality, while the least popular mode of governance is the PAMB system of centralised national management. Figure 4.2 shows conclusively that the islanders would like to see the Barangay take the lead in coastal resource management, preferably in a co-management relationship with the municipality (average score 7.78). It also shows that although people would accept national government in combination with the Barangay and the municipality (this option scored 5.38), their least preferable option was the one occurring currently - top-down governance by the national state government, i.e. the PAMB - which scored 1.73, by far the lowest rating of all. Significantly, of the eight alternatives, respondents' first four preferences were for governance modes which included the Barangay, either in combination with other modes or by itself. Also significant was the finding that respondents would prefer no fisheries governing body at all to the PAMB. One focus group respondent claimed that "there will be a riot if PAMB stays here...Blood will be spilt". Another said "the people are boiling over PAMB". This finding accords with the conclusion of a study into a conservation project in Turtle Islands, Philippines, that the unpopularity of the top-down regime lay in its failure to respect local sensibilities [21].

On the other hand, the questionnaire survey revealed that $72.2 \%$ of respondents rated NIPAS as 'good' or 'very good' for Apo. This favourable verdict is supported by qualitative evidence of residents praising the PAMB and blaming external forces, such as increases in global rice prices, for the socioeconomic downturn on the island. Criticism of the previous community-based management was also voiced by a sizeable minority, who accused Barangay leaders of authoritarian tendencies. One interviewee, an attorney specialising in environmental law, reported that NIPAS was introduced partly to combat political interference with environmental management, a charge levelled at the communitybased management system with members of opposing political parties accusing rival leaders of only employing their allies in key MPA management positions.

\section{Discussion}

Discussion focuses on three issues: first, how can the above apparently contradictory findings of respondents' overall verdict on the PAMB be reconciled? Second, what are the implications of the study's findings for Apo? Third, what are the implications beyond Apo?

On the first issue, the above apparently contradictory opinions about NIPAS reflect the different perspectives of respondents. The group most hostile to NIPAS are the Barangay council, which is hardly surprising, since NIPAS displaced them from wielding power during the community-led period of management. The rest of the population was more ambiguous in its view of NIPAS, critical of its 
exclusivity, lack of transparency, and suspected corruption, but appreciative of its socio-economic benefits and (fair) ecological record. It was also ambiguous in its view of the Barangay's past role in community-base management, mindful of its sometimes murky dealings. There is little doubt that people believed in the concept of the MPA: indeed, ever since the initial education sessions run by Silliman University informed Aponians that marine protection would help the fishery, they were in favour of the MPA: as one elderly woman said, she "fell in love with the idea of the sanctuary, as there would be many fishes" (79.5\% of respondents believed that enhancing fisheries was the purpose of marine protection). But it seems that while respondents saw both NIPAS and community-based management $(\mathrm{CBM})$ as theoretically promising modes of environmental protection, in practice both were flawed in the hands of PAMB and the Barangay, respectively. Villagers were asked to characterise four historical periods of fisheries management in Apo, coding their responses as positive, negative or neutral. Table 5.1 shows that the periods before CBM (pre-1976, where there was no fisheries governance at all) and the period of PAMB management (1994-present) are negatively viewed; whilst the eras of education by Silliman University (1976-82) and community-based management under the Local Government Code (1982-94), are positively viewed by local stakeholders. But the mode of governance that appears to be most favoured is co-management - a compromise or middle ground [9] between top-down and bottom-up. It seems that Apo people do not fully trust either extreme of top-down or bottom-up governance, and see co-management as a means of restraining both tendencies.

\section{TABLE 5.1 PLACED HERE}

On the second issue - the implications of the findings for Apo - a key paper [17] tells the story of how Apo Island became one of the world's best community-based MPAs through a bottom-up orientated 'New People Power Revolution'. The results of the present study show that the will of Apo residents to continue the environmental protection motivating that revolution has not diminished, but they also show that the people power revolution itself has ceased. The declaring of the island as Apo Island Protected Landscape and Seascape under NIPAS brought a top-down governance system, displaying the centralisation, bureaucracy and elitism typical of 'state-centric' or 'directive' governance. Introduced to protect the island's environmental policy from potential damage inflicted by the community-based management system dominated by the Barangay, it has itself been accused of compromising the island's environmental future. Critics of NIPAS, while not denying the potential danger to the environment posed by the political division and corruption during the community-based management era, ask why the DENR and national government chose to radically change the governance mode, rather than find a less dramatic solution through a modification of the existing bottom-up governance structure that was so highly regarded. In a telling remark, a former Barangay leader argued that "NIPAS is only effective in a place where there is no community". By excluding the Barangay and its residents from all participation in decision-making, the PAMB has transformed the atmosphere in the community from relative contentment and peace, to alienation and disempowerment as people struggle to maintain their quality of life. During community-based management, residents readily followed environmental regulations, but now they increasingly threaten to break the PAMB's extensive and largely unexplained prohibitions, in order to safeguard their living standards and personal freedoms. The General Management Plan [8] contains some of the environmental regulations that are necessary for the sustainable future of the island, but for them to be legitimised, they must be understood and accepted by a co-management system, not imposed by the command-and-control format of the present regime.

The implications for Apo if the current system remains in place are not propitious. One of the main reasons why the marine environment is still at a high standard in Apo is that, although excluded from management decision-making, the local population have continued to practise voluntary stewardship. But this voluntary stewardship cannot be taken for granted indefinitely, because the increasing unpopularity of PAMB may at some stage lead Apo fishers to resume destructive fishing practices, and it is doubtful whether PAMB would have the authority to deal effectively with such a situation. The solution is for DENR to authorise PAMB to open its membership to stakeholders from the local community, thereby establishing a form of cooperative or co-management [22]. Given the Philippine government's anxiety about the danger of another Sumilon, and given the Apo people's own preference for co-management by the barangay and municipality, it is not feasible to return to the communitybased management mode [23]. A better option is for some elements of community-based management to be reintroduced, to co-exist with a modified form of PAMB's state-centrism, to form a system of comanagement [9]. This is the best of both worlds, incorporating elements of both bottom-up and top- 
down governance, while avoiding the extremes of either. Significantly, as noted above, comanagement, not community-based management, is the mode of governance most favoured by Apo residents.

On the third issue - the implications of these findings beyond Apo - they reinforce the results of other studies that emphasise the important roles that both community and state play in coastal resource management [24]. As a community-based MPA, the positive message of Apo was cited by many writers [25] [26] in support of their argument that community-based MPAs should be a key part of the Philippines coastal resource management policy. The performance of PAMB has cast doubt on the wisdom of replacing community-based management with a state-centric system of management, and explains why the NIPAS Act was rejected in Coron, where the prospect of NIPAS designation caused so much local resentment that it was never declared [27]. However, the optimal solution is not pure community-based management, which risks what Lane \& Corbett call the "tyranny of localism" [23], and what Jones and Burgess call "the risks of parochialism" [28], but a mixture of it with state supervision. Designation of further protected areas under NIPAS (in its current format) is thus inadvisable, as the Act does not provide the framework for the bottom-up decision making required for co-management. The law must either be re-written to allow for co-management to take place, or new legislation must be created that allows this to occur. Legislation such as this would not just remedy the problems currently affecting the management of Apo, but would also provide an institutional framework from which other failing Philippine MPAs could be managed (such as Sumilon). A Philippine law that aids successful MPA management could be a vital model for legislative reform in countries with similar problems managing MPA networks.

\section{Conclusion}

Apo can no longer be considered as one of the world's best run MPAs. Introducing top-down governance through the mandate of the NIPAS Act has created problems that could turn out to be as serious as the potential problems that it was designed to prevent, and if Apo is to regain its former status, it must decentralise its management. If MPAs are to be a successful part of Philippine's sustainable resource management policy in the future, the NIPAS Act must be reviewed and replaced with legislation that shares decision-making powers between the national state and the local community.

\section{Acknowledgments}

This paper was part-funded by the National Environmental Research Council, UK. Thanks are due to the people of Apo Island, the Mayor of the town of Dauin, the DENR and the staff of Silliman University, especially Dr. Enrique G. Oracion, without whose generous co-operation this study would not have been possible.

\section{References}

[1] Roberts CM. Ecological advice for the global fisher crisis. Trends in Ecology and Evolution 1997; 12: 35-8.

[2] Kelleher G, Bleakley C, Wells S. A global representative system of marine protected areas. The World Bank, Washington; 1995.

[3] McClanahan TR. Is there a future for coral reef parks in poor tropical countries? Coral Reefs 1999; 18: 321-5.

[4] Local Government Code 1991 (Republic Act 7160). Manila: Congress of the Philippines.

[5] The Philippine Fisheries Code 1998 (Republic Act 8550). Manila: Congress of the Philippines.

[6] Christie P. The Philippines: Lessons for marine protected area governance and effective design in the role of marine protected areas. In: World Bank Environment Department, commissioning body. Scaling up marine management: The role of marine protected areas. Washington DC: World Bank; 2006. p. 31-44.

[7] National Integrated Protected Area Systems Act 1992 (Republic Act 7586). Manila: Congress of the Philippines.

[8] Apo Island Protected Area Management Board. Apo Island Protected Landscape and Seascape general management plan. Dumaguete, Philippines: Department of Environment and Natural Resources 2007.

[9] Jones, PJS. Marine protected area strategies: issues, divergences and the search for middle 
ground. Reviews in Fish Biology and Fisheries 2002; 11: 197-216.

[10] Russ GR, Alcala AC. Management histories of Sumilon and Apo Marine Reserves, Philippines, and their influence on national marine resource policy. Coral Reefs 1999; 18: 307-19.

[11] Russ GR, Alcala AC, Maypa AP, Calumpong HP, White AT. Marine reserve benefits local fisheries. Ecological Applications 2004; 14: 597-606.

[12] White AT, Calumpong HP. Summary Field Report. Saving Tubbataha Reef. Monitoring marine reserves in the central Visayas. Earthwatch Expedition, Philippines, April-May 1992.

[13] White AT, Vogt HP, Arin T. Philippine coral reefs under threat: The economic losses caused by reef destruction. Marine Pollution Bulletin 2000; 40: 598-605.

[14] Chuenpagdee R, Fraga J, Euán-Avila JI. Progressing toward co-management through participatory research. Society and Natural Resources 2004; 17: 147-61.

[15] Johannes RE, Freedman MMR, Hamilton RJ. Ignore fisher's knowledge and miss the boat. Fish and Fisheries 2000; 1: 257-271.

[16] Fischer F, Reframing public policy: discursive politics and deliberative practice. New York: Oxford University Press; 2003.

[17] Alcala AC, Russ GR. No-take marine reserves and reef fisheries management in the Philippines: A new people power revolution. Ambio 2006; 35: 245-54.

[18] Leisher C, van Beukering P, Scherl LM. Nature's investment bank: How marine protected areas contribute to poverty reduction. Arlington, USA: The Nature Conservancy; 2007.

[19] Oracion EG. Are the children willing? Intergenerational support for marine protected area sustainability. Silliman Journal 2006; 47: 48-74.

[20] White AT, Christie P, Meneses A, Ovenden M, Tesch S, White E, Apurado J. Summary Field Report, Saving Philippine Reefs. Coral Reef Monitoring Surveys for Conservation in Cebu, Negros Oriental, and Siquijor, Philippines March 23-31 2002. [Online] Available at: http://www.coast.ph/MPAdb/showcpsk.asp?code=347\&dc=na\&yr=205 [Accessed 21 July 2008].

[21] Lejano, RP, Ingram, HM, Whiteley, JM, Torres, D, Agduma, SJ. The importance of context: integrating resource conservation with local institutions. Society and Natural Resources 2007; 20: $177-185$

[22] Wilson, DC, Raakjaer Nielsen, J, Degnbol, P. Editors. The Fisheries Co-Management Experience. Dordrecht, Kluwer.

[23] Lane, MB, Corbett, T. The tyranny of localism: indigenous participation in community-based environmental management. Environmental Policy and Planning 2005; 7 (2): 141-159

[24] Walters, BB. Local management of mangrove swamps in the Philippines: successful conservation or efficient resource exploitation? Human Ecology 2004; 32 (2): 177-195

[25] Pollnac RB, Crawford BR, Gorospe MLG. Discovering factors that influence the success of community-based marine protected areas in the Visayas, Philippines. Ocean and Coastal Management 2001; 44: 683-710.

[26] Christie P, White AT, Deguit E. Starting point or solution? Community-based marine protected areas in the Philippines. Journal of Environmental Management 2002; 66: 441-54.

[27] Ferrari MF, de Vera D. A choice for indigenous communities in the Philippines. Human Rights Dialogue [online] 2004; 2: Available at: http://www.cceia.org/resources/publications/dialogue/2_11/online_exclusive/4457.html (Carnegie Council) [accessed 24 June 2008].

[28] Jones, PJS, Burgess, J. Building partnership capacity for the collaborative management of marine protected areas in the UK: a preliminary analysis. Journal of Environmental Management 2005; 77: 227-243. 
Table 2.1. Livelihood activities of Apo residents. Measured as households involved in livelihood.

\begin{tabular}{|l|l|l|l|}
\cline { 2 - 4 } \multicolumn{1}{c|}{} & \multicolumn{2}{l|}{ Households Involved in Livelihood (\%) } \\
\hline Locality & Fishing & Tourism & MPA Management \\
\hline Purok 1 & 63 & 84 & 42 \\
\hline Purok 2 & 81 & 63 & 31 \\
\hline Purok 3 & 67 & 87 & 33 \\
\hline Purok 4 & 70 & 55 & 45 \\
\hline Purok 5 & 85 & 30 & 11 \\
\hline Purok 6 & 91 & 39 & 30 \\
\hline Purok 7 & 83 & 22 & 33 \\
\hline Whole Barangay & 77 & 54 & 32 \\
\hline
\end{tabular}


Table 5.1. Residents' opinions of management periods (interpreted from qualitative descriptions).

\begin{tabular}{|l|l|l|l|l|}
\hline & \multicolumn{2}{|l|}{ Perception of management (\%) } \\
\hline & Pre-1976 & $1976-82$ & $1982-94$ & 1994-present \\
\hline Positive & 28.6 & 72.5 & 65.3 & 24.5 \\
\hline Neutral & 28.6 & 27.5 & 26.7 & 25.9 \\
\hline Negative & 42.9 & 0.0 & 7.9 & 49.7 \\
\hline
\end{tabular}


Table 4.1. Institutional ratings for environmental management.

\begin{tabular}{|l|l|l|}
\cline { 2 - 3 } \multicolumn{1}{c|}{} & \multicolumn{2}{l|}{ Management Task (average score out of 10) } \\
\cline { 2 - 3 } \multicolumn{1}{c|}{} & Reef Management & Boat Control \\
\hline Apo Residents & 7.76 & 8.24 \\
\hline Barangay Officials & 7.53 & 7.92 \\
\hline Municipal Officials & 6.74 & 7.29 \\
\hline PAMB & 6.45 & 7.10 \\
\hline SU & 7.71 & 8.33 \\
\hline
\end{tabular}


Figure 2.1. Map of Apo Island with Puroks (1-7) and other features displayed.

Figure 2.2. Timeline showing key management and legislative changes at Apo Island.

Figure 4.1. Textual analysis of CRM documents - Themes: Bottom-up rhetoric and power; top-down rhetoric and power.

Figure 4.2. Survey respondents' preference of governing institutions(s). 